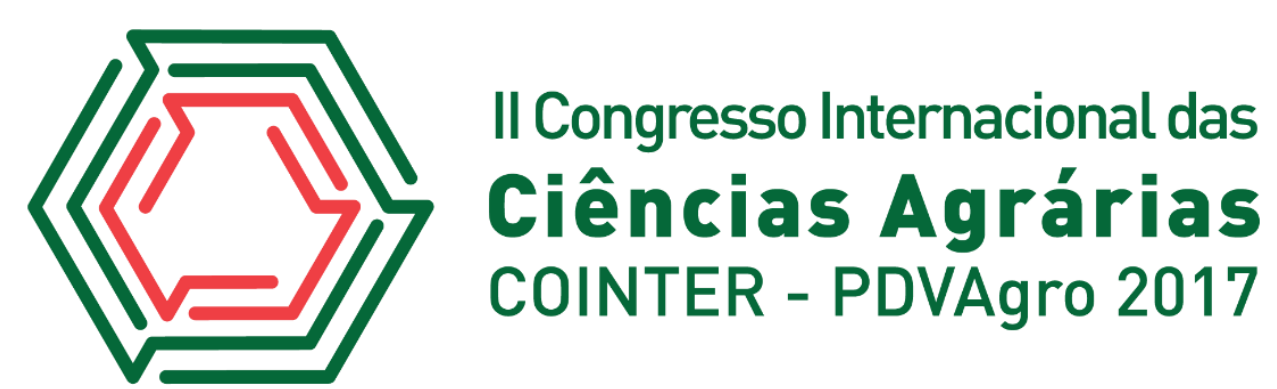

\title{
AVALIAÇÃO DOS ATRIBUTOS FISICOS DO SOLO NA ÁREA EXPERIMENTAL SOBRE CULTIVO DA BANANA (Musa paradisíaca) NO IFPE-CAMPUS VITÓRIA DE SANTO ANTÃO.
}

Apresentação: Pôster

\begin{abstract}
José Denilson da Silva ${ }^{1}$; Igor Almir Silva Gonçalves ${ }^{2}$; Carlos Tomaz Tavares Silva ${ }^{3}$; Luis Felipe Silva Menezes ${ }^{4}$; Sandro Augusto Bezerra ${ }^{5}$
\end{abstract}

\section{Introdução}

A banana destaca-se na primeira posição no ranking mundial das frutas, com uma produção de 106,5 milhões de toneladas. O Brasil produz sete milhões de toneladas, com participação de 6,9\% nesse total VIEIRA (2015, apud IBGE, 2014). A banana é a segunda fruta mais consumida no planeta, com 11,4 kg/hab/ano, perdendo apenas para a laranja, com 12,2 kg/hab/ano. O continente americano é o maior consumidor, com 15,2 kg/habitantes/ano, destacando-se a América do Sul, com $20 \mathrm{~kg} /$ habitantes/ano e a América Central, com 13,9 kg/habitantes/ano VIEIRA (2015, apud FAO, 2013).

A produtividade pode ser afetada por diversos fatores, entre eles se destacam os fatores de manejo solo, e seus atributos, dentre os principias destacando-se a densidade do solo que é definida como sendo a relação existente entre a massa de uma amostra de solo seca a $105^{\circ} \mathrm{C}$ e a soma dos volumes ocupados pelas partículas e pelos poros (Borges, 2004). Duas propriedades físicas, hierarquicamente mais importantes, referem-se a textura do solo, que é definida pela distribuição de tamanho de partículas, e a estrutura do solo definida pelo arranjamento das partículas em agregados (REINERT 2006).

Segundo (Robinson, 1995), a porosidade do solo, por sua vez, é responsável por um conjunto de fenômenos e desenvolve uma série de mecanismos de importância na física de solos, tais como retenção e fluxo de água e ar, e, se analisada conjuntamente com a matriz do solo, gera um grupo de outras propriedades físicas do solo associadas às relações de massa e volume das fases

\footnotetext{
1 Bacharelado em Agronomia, IFPE-Campus Vitória de Santo Antão, denisonsila@gmail.com 2 Bacharelado em Agronomia, IFPE-Campus Vitória de Santo Antão, iasgon99@gmail.com 3 Bacharelado em Agronomia, IFPE-Campus Vitória de Santo Antão, Carlosthomaztavares@gmail.com 4 Bacharelado em Agronomia, IFPE-Campus Vitória de Santo Antão, luisfelipemenezes@gmail.com 5 Dr. Ciências do solo, IFPE-Campus Vitória de Santo Antão, sandro.augusto@vitoria.ifpe.edu.br
} 
do sistema solo, a produtividade pode ser afetada pelos fatores citados, pois o sistema radicular das plantas não consegue se desenvolver, limitando a absorção de nutrientes e água pela planta.

A avaliação da compactação é baseada na condição atual em que se encontra o solo, onde é possível identificar camadas que apresentam restrições ao crescimento e produtividade das culturas (CAVALCANTE et al., 2011; MION et al., 2012), podendo ser evidenciada por vários atributos físicos do solo, tais como: densidade, porosidade, textura e resistência à penetração (MION et al.,2012).

De acordo com Vieira (2004), a variabilidade espacial de solos sempre existiu e deve ser considerada toda vez que a amostragem de campo for efetuada, pois pode indicar locais que necessitam de tratamento diferenciado quanto ao manejo, sem prejuízo para a representatividade, possibilitando maior detalhamento de uma determinada área. O presente trabalho tem como objetivo avaliar os atributos físicos na área experimental na cultura da banana no IFPE-Campus Vitória de Santo Antão

\section{Fundamentação Teórica}

A bananeira é uma planta sensível aos fatores de crescimento ligados à física do solo, como aeração, água, temperatura do solo e resistência mecânica ao crescimento das raízes (Delvaux, 1995). O decréscimo na disponibilidade de oxigênio no solo cultivado com bananeira, seja por compactação ou encharcamento, prejudica o sistema radicular da planta, já que, em tais condições, ocorre rapidamente a morte de raízes. Sabe-se que as raízes da bananeira somente utilizam água retida a baixo dos valores de tensão no solo (Robinson, 1995).

Os efeitos da compactação sobre as características e propriedades do solo evidenciam aumento na densidade, redução na porosidade total, bem como na infiltração e no armazenamento de água nele (Dias Junior \& Pierce, 1996) e restrição ao fluxo de gases e aumento na resistência ao crescimento de raízes (Hamza \& Anderson, 2005).

As evidências experimentais conduzem ao fato de que a bananeira é muito afetada pelo déficit hídrico, rapidamente entrando em estresse. O manejo da água no solo deve ser realizado no sentido de que a água disponível às plantas se situe, no máximo, entre 30\% e 35\% (maior para períodos frios e menor para períodos quentes e secos), dependendo da demanda atmosférica, e que, em média, o potencial da água no solo não seja menor do que $-30 \mathrm{kPa}$ na profundidade 0 a $40 \mathrm{~cm}$ 
(Coelho et al., 2004).

A compactação do solo interfere no desenvolvimento das plantas, quando um solo não saturado é submetido a determinada pressão, ocasionando redução de volume com consequente aumento de densidade, ocorre o processo de compactação do solo (Gupta \& Allmaras, 1987). O arranjo estrutural do solo, a consistência, a porosidade total, o número e tamanho dos poros e a difusão de gases são afetados pela compactação, que, por conseqüência, afeta o crescimento das raízes (Taylor \& Brar, 1991).

\section{Metodologia}

O solo foi coletado de uma área experimental no Instituto Federal de Pernambuco, campus Vitória de Santo Antão. A coleta foi realizada utilizando-se anéis volumétricos, o solo foi coletado de três pontos diferentes da área e com duas profundidades diferentes, de 0-10 cm e de 10-20 cm.

As análises foram realizadas no laboratório de física do solo do IFPE - Campus Vitória. Foram utilizados anéis volumétricos para a obtenção do solo na área e em seguida posto para secar em uma estufa por 24 horas a $180^{\circ} \mathrm{c}$, a medida do diâmetro do cilindro, altura e peso do solo foram retirados antes de irem para estufa. Depois de $24 \mathrm{~h}$ o solo foi retirado do cilindro e passou por peneira de 0,2ml. Quando destorroado, foi pesado em uma balança e separado em três partes contendo 20 gramas g de cada área e profundidade. Assim que separados as $20 \mathrm{~g}$, foi colocado em álcool através de uma pipeta graduada, para realizar a medição de densidade de partículas.

A determinação da Porosidade Total $(\mathrm{Pt})$ foi retirada pela formula PT=(1- (DS*DP).100. onde tiramos a diferença entre os valores e obtenção dos valores calculados.

\section{Resultados e Discussões}

Os resultados das análises do solo apresentaram, uma densidade de solo alta para solos com alto teor de argila, isso mostrou que o solo apresenta início de compactação nas camadas de 0-10 e 10-20cm, como podemos ver na tabela 1. Valores de Densidade de solo associados ao estado de compactação com alta probabilidade de oferecer riscos de restrição ao crescimento radicular situamse em torno de $1,65 \mathrm{~g} \mathrm{~cm}^{-3}$ para solos arenosos e $1,45 \mathrm{~g} \mathrm{~cm}^{-3}$ para solos argilosos. (Reinert 2006). $\mathrm{O}$ solo apresentou uma baixa quantidade de poros, isso é devido a compactação do solo um pouco acima da ideal, solos muito densos tendem a diminuir a porosidade dos solos, que acarreta na diminuição da umidade real. Apesar dos solos argilosos possuírem maior capacidade de retenção de água que os solos arenosos, esta umidade não está totalmente disponível para as plantas em 
crescimento (Lorenzo 2009). Os efeitos da compactação sobres as propriedades do solo evidenciam aumento na densidade, redução na porosidade total, bem como na infiltração e no armazenamento de água nele (Dias Junior \& Pierce, 1996)

TABELA 1. Atributos físicos do solo analisados na cultura da bananeira: A1(Amostra 1 de 0-10cm) A2 (Amostra 1 de 10-20 cm) B1 (Amostra 2 de 0-10 cm) B2 (Amostra 2 de 10-20 cm) C1(Amostra 3 de 0-10cm) C2 (Amostra 3 de 10-20cm). Ds (Densidade do Solo; DP (Densidade de Partículas); PT (Porosidade Total).

\begin{tabular}{cccc}
\hline Amostra & DS (g/cm3) & DP (g/cm3) & PT (\%) \\
\hline A1 & 1,63 & 2,17 & 24,88 \\
A2 & 1,72 & 2,35 & 26,98 \\
B1 & 1,85 & 2,48 & 25,53 \\
B2 & 1,67 & 2,46 & 31,81 \\
C1 & 1,62 & 2,54 & 36,28 \\
C2 & 1,97 & 2,46 & 20,08 \\
\hline
\end{tabular}

\section{Conclusões}

A densidade de solo apresentou valores acima do ideal nas duas camadas avaliadas, contribuindo paras as alterações dos outros atributos físicos do solo, com a continuação do manejo utilizado poderá acarretar na compactação, o que inviabilizará a continuidade do plantio da cultura da banana na área.

\section{Referências}

AGRIANUAL 2001: anuário estatístico da agricultura brasileira. São Paulo: FNP Consultoria \& Comércio, 2001. 492p

CAVAlCANTE, E. G. S.; AlveS, M. C.; SOUZA, Z. M.; PEREIRA, G. T.. Variabilidade espacial de atributos físicos do solo sob diferentes usos e manejos. Engenharia Agrícola e Ambiental, v.15, n.3, p.237-243, 2011.

COELHO, E. F; COSTA, E. L. da; TEIXEIRA, A. E. de C. In: BORGES, A. L.; SOUZA, L. da S. (Ed.). O cultivo da bananeira. Cruz das Almas: Embrapa Mandioca e Fruticultura, 2004. p. 32-44.

DEBIASI, H.; LEVIEN, R.; TREIN, C.R.; CONTE, O. \& MAZURANA, M. Capacidade de suporte e compressibilidade de um Argissolo, influenciadas pelo tráfego e por plantas de cobertura de inverno. R. Bras. Ci. Solo, 32:2629-2637, 2008. 
DELVAUX, B. Soils. In: GOWEN, S. (Ed.). Bananas and plantains. London: Chapman \& Hall, 1995. cap. 9, p. 230-257.

DIAS JUNIOR, M.S. \& PIERCE, F.J. O processo de compactação do solo e sua modelagem. R. Bras. Ci. Solo, 20:175-182, 1996.

GUPTA, S. C.; ALLMARAS, R. R. Models to access the susceptibility of soil to excessive compaction. Advances in Soil Sciences, New York, v. 6, p. 65-100, 1987.

HAMZA, M.A. \& ANDERSON, W.K. Soil compaction incropping systems: A review of the nature, causes and possible solutions. Soil Till. Res., 82:121-145, 2005.

IBGE - Instituto Brasileiro de Geografia e Estatística) Levantamento sistemático da produção agrícola. Rio de Janeiro: IBGE, Anos consultados: 1986 a 1997.

IBGE - Instituto Brasileiro de Geografia e Estatística) Levantamento sistemático da produção agrícola. Rio de Janeiro: IBGE, Anos consultados: 1986 a 1997.

Reinert, D.J, Propriedades físicas do solo, Universidade Federal de Santa Maria, Centro de Ciências Rurais,. 1997

ROBINSON, J. C. Systems of cultivation and management. In: GOWEN, S. (Ed.). Bananas and plantains. London: Chapman \& Hall, 1995. cap. 2, p. 1565.

TAYLOR, H. M.; BRAR, G. S. Effect of soil compaction on root development. Soil and Tillage Research, Amsterdam, v. 19, p. 111-119, 1991.

VIEIRA, S.R, Analise de variabilidade especial e temporal de umidade do solo em latossolo vermelho eutroférrico em Campinas, São Paulo. Campinas, 2004. 54f (Relatório FAPESP 02/ 02863-3)

Vieira, Luiz Marcelino. Brasil é o terceiro maior produtor de banana. Campo \& negócios, Brasil, 31 Jan. 2015. Disponível em: http://www.revistacampoenegocios.com.br/brasil-e-o-terceiro-maiorprodutor-de-banana/. Acesso em: 20 Set. 2017

ROBINSON, J. C. Systems of cultivation and management. In: GOWEN, S. (Ed.). Bananas and plantains. London: Chapman \& Hall, 1995. cap. 2, p. 1565. 